\title{
O FRACASSO ESCOLAR À LUZ DA TEORIA HISTÓRICO-CULTURAL: REFLEXÕES ACERCA DA CULPABILIZAÇÃO DO ALUNO
}

\author{
Tamara de Lima ${ }^{1}$, Leandro Aparecido de Souza ${ }^{2}$ \\ ${ }^{1}$ Doutoranda em Educação pela Universidade Estadual Paulista - Unesp, Presidente Prudente, SP. Professora do \\ Ensino Básico, Técnico e Tecnológico no Instituto Federal de Educação, Ciência e Tecnologia de São Paulo - IFSP, \\ Campus Presidente Epitácio. ORCID iD: https://orcid.org/0000-0001-9839-3217 . E-mail: tamara.lima@ifsp.edu.br \\ ${ }^{2}$ Doutorando em Educação pela Universidade Estadual Paulista - UNESP, Presidente Prudente, SP. Servidor Público \\ Federal desde 2010, atua como Técnico em Assuntos Educacionais no Instituto Federal de Educação, Ciência e \\ Tecnologia de São Paulo - IFSP, Campus Birigui. ORCID iD: http://orcid.org/0000-0002-6939-5501. E-mail: \\ leandrosouza@ifsp.edu.br
}

\section{RESUMO}

O fracasso escolar se configura como objeto de debate em diferentes âmbitos educacionais e políticos. Apesar das discussões, trata-se de um problema que está distante de uma resolução e que merece a atenção dos pesquisadores. Pesquisas na área educacional têm apontado que as explicações para o fenômeno estão centralizadas no aluno e/ou em sua família. Sendo assim, o objetivo deste ensaio teórico é problematizar a concepção de que o fracasso escolar é de responsabilidade única e exclusivamente do aluno, e as visões naturalizantes e positivistas acerca do ser humano, na tentativa de sua superação. 0 referencial teórico e metodológico ao qual nossa análise buscou aporte é a teoria histórico-cultural e, por conseguinte, o materialismo histórico dialético. Analisamos especificamente as dimensões sociais e psicológicas do fracasso escolar para além da responsabilização do aluno e de sua família, considerando a totalidade do ser social e as condições objetivas da realidade concreta. Lançar um olhar crítico sobre o fenômeno do fracasso escolar implica em revelar nossa dificuldade enquanto sociedade, corporificada em nossos sistemas de ensino, instituições escolares e profissionais da educação em lidar com os desafios advindos da democratização do ensino, ou seja, com o acesso das camadas populares à escola pública. Dessa forma, o fracasso escolar acaba sendo tratado como um problema de cunho individual isentando de responsabilidade os demais envolvidos no processo de escolarização.

Palavras-chave: Fracasso escolar. Culpabilização. Aluno. Teoria histórico-cultural. Materialismo histórico dialético.

\section{SCHOOL FAILURE IN THE LIGHT OF HISTORIC-CULTURAL THEORY: REFLECTIONS ABOUT STUDENT CULPABILIZATION}

\section{ABSTRACT}

School failure is an object of debate in different educational and political spheres. Despite the discussions, it is a problem that is far from a resolution and deserves the attention of researchers. Research in the educational area has pointed out that the explanations for the phenomenon are centered on the student and/or his family. Thus, the aim of this theoretical essay is to problematize the conception that school failure is the sole and exclusive responsibility of the student, and the naturalizing and positivist views about the human being, in an attempt to overcome it. The theoretical and methodological framework to which our analysis sought support is the historical-cultural theory and, therefore, dialectical historical materialism. We specifically analyze the social and psychological dimensions of school failure beyond the accountability of the student and his family, considering the totality of social being and the objective conditions of concrete reality. Taking a critical look at the phenomenon of school failure implies revealing our difficulty as a society, embodied in our education systems, school institutions and education professionals in dealing with the challenges arising from the democratization of education, that is, with 
the access of the popular classes to the public school. Thus, school failure ends up being treated as an individual problem, exempting the others involved in the schooling process from responsibility.

Keywords: School failure. Culpabilization. Student. Historical-cultural theory. Dialectical historical materialism.

\section{FRACASO ESCOLAR A LA LUZ DE LA TEORÍA HISTÓRICO-CULTURAL: REFLEXIONES SOBRE LA CULPABILIZACIÓN DE ESTUDIANTES}

\section{RESUMEN}

El fracaso escolar es objeto de debate en diferentes ámbitos educativos y políticos. A pesar de las discusiones, es un problema que está lejos de una resolución y merece la atención de los investigadores. La investigación en el área educativa ha señalado que las explicaciones del fenómeno se centran en el estudiante y/o su familia. Por lo tanto, el objetivo de este ensayo teórico es problematizar la concepción de que el fracaso escolar es responsabilidad única y exclusiva del estudiante, y las opiniones naturalizadoras y positivistas sobre el ser humano, en un intento de superarlo. El marco teórico y metodológico en el que nuestro análisis buscó apoyo es la teoría histórico-cultural y, por lo tanto, el materialismo histórico dialéctico. Analizamos específicamente las dimensiones sociales y psicológicas del fracaso escolar más allá de la responsabilidad del estudiante y su familia, considerando la totalidad del ser social y las condiciones objetivas de la realidad concreta. Una mirada crítica al fenómeno del fracaso escolar implica revelar nuestra dificultad como sociedad, incorporada en nuestros sistemas educativos, instituciones escolares y profesionales de la educación para enfrentar los desafíos que surgen de la democratización de la educación, es decir, con el acceso de las clases populares a la escuela pública. Por lo tanto, el fracaso escolar termina siendo tratado como un problema individual, eximiendo de responsabilidad a los demás involucrados en el proceso escolar.

Palabras clave: Fracaso escolar. Culpabilización. Alumno. Teoría histórico-cultural. Materialismo histórico dialéctico.

\section{INTRODUÇÃO}

As pesquisas na área da educação têm se voltado a investigar o fenômeno educativo interrogando-o por diferentes e variadas lentes, a fim de obter respostas que façam avançar e progredir a área, na busca de soluções, não somente para as problemáticas apresentadas na prática, como também de alternativas para o seu aperfeiçoamento. Dentre os questionamentos levantados pelos trabalhos desenvolvidos pelos pesquisadores, para além de questões relacionadas à formação inicial e continuada docente, aos processos de ensino e aprendizagem ou às políticas educacionais, encontramos aquelas cujas temáticas debatem 0 fracasso escolar.

O primeiro ponto que devemos discutir e problematizar sobre o assunto é o que essas pesquisas têm entendido por fracasso escolar, temática amplamente estudada em diversos países. A expressão tem sido utilizada para se referir a uma série de fenômenos educacionais designados por termos e expressões como: baixo rendimento escolar, aquisição insuficiente de conhecimentos, defasagem na relação idade- série, reprovação, retenção, repetência, evasão, dentre outros (ZAGO, 2011; PEZZI; MARIN, 2017).

Nesse sentido, a Organização para a Cooperação e Desenvolvimento Econômico (OCDE) destaca que "o fracasso escolar penaliza uma criança por toda a sua vida, uma vez que ela deixa de estar em nível de igualdade com as demais, acarretando futuramente, empregabilidade em ocupações com salários mais baixos e, consequentemente, aposentadoria inferior" (PEZZI; MARIN, 2017). Ainda, de acordo com essa Organização (1998):

$$
\begin{aligned}
& \text { Independente das } \\
& \text { diferenças no uso do } \\
& \text { termo, o fracasso escolar } \\
& \text { precisa ser considerado } \\
& \text { como um processo, que } \\
& \text { pode envolver três } \\
& \text { momentos. O início se dá } \\
& \text { quando o aluno tem } \\
& \text { desempenho inferior à } \\
& \text { média e precisa repetir um } \\
& \text { ano escolar; o segundo } \\
& \text { acontece no momento em } \\
& \text { que ele acaba por evadir o } \\
& \text { sistema escolar antes de } \\
& \text { completar a escolaridade }
\end{aligned}
$$


obrigatória; e, por fim, quando repercute na vida profissional devido à falta de conhecimentos básicos que deveriam ter sido aprendidos na escola. (PEZZI; MARIN, 2017, p. 3).

Dados do Instituto Nacional de Estudos e Pesquisas Educacionais Anísio Teixeira (Inep) coletados pelo Censo Escolar em 2018 acerca da Educação Básica -, revelam que um total de 1,5\% dos alunos matriculados no ensino fundamental (1ㅇ ao 9o ano) abandonou a escola, índice que pode ser considerado baixo. Já a taxa de reprovação foi mais alta: média de $7,0 \%$, sendo de $5,1 \%$ nos anos iniciais ( 1 - ao 5 - ano) e de $9,5 \%$ nos anos finais (6o ao 9o ano). Ao analisar os índices de evasão e retenção do ensino médio, o fenômeno apresenta-se mais grave, sendo que $6,1 \%$ dos alunos matriculados nesse nível de ensino abandonou a escola no ano de 2018. Essa taxa foi de $7,9 \%, 5,6 \%$ e $4,1 \%$ no 1 으, 2으 e 3o ano do ensino médio, respectivamente. Já as taxas de reprovação apresentaram-se ainda mais altas, com um total de $10,5 \%$, sendo de $15,4 \%, 9,4 \%$ e $5,4 \%$ no 1ㅇ, 2ㅇ e 3 o ano do ensino médio, respectivamente (BRASIL, 2019).

Mas, para além dos dados oficiais de evasão e retenção, é necessário refletir sobre a dimensão da não-aprendizagem, uma vez que sabemos que a aprovação de uma série para outra muitas vezes não é acompanhada de um aprendizado efetivo. Em 2018, na aplicação das provas do Programa Internacional de Avaliação dos Estudantes (Pisa) - avaliação realizada de forma amostral com estudantes matriculados a partir do 70 ano do ensino fundamental na faixa etária dos 15 anos -, constatou-se que um percentual elevado dos estudantes brasileiros não possuem nível básico em matemática, ciências e leitura, respectivamente $68,1 \%, 55,0 \%$ e $50,0 \%$ (BRASIL, 2019). Por mais que os resultados dessas avaliações em larga escala possam ser questionáveis, é fato notório que muitos de nossos alunos têm concluído o ensino médio com sérias deficiências nas diferentes áreas do conhecimento.

No âmbito deste artigo, portanto, corroborando os estudos sobre a temática, o fracasso escolar é entendido segundo a dimensão da não-aprendizagem, o que muitas vezes acarreta reprovação - a depender dos diferentes sistemas de ensino vigentes no país - e evasão escolar. O fracasso escolar se configura como objeto de debate em diferentes âmbitos educacionais e políticos. Apesar das discussões, trata-se de um problema que está distante de uma resolução e que merece a atenção dos pesquisadores.

O segundo ponto importante que devemos trazer à tona nessa discussão - e ao qual nos propomos a analisar mais detidamente ao longo deste estudo - diz respeito às atribuições causais para o fracasso escolar. As pesquisas sobre o tema vêm constatando que o próprio aluno é visto como o único ou o grande responsável pelo fracasso ou o sucesso escolar. Essa visão é compartilhada por professores e também pelos próprios alunos.

Para citar algumas pesquisas sobre o tema, Gama e Jesus (1994) investigaram as atribuições de causalidade e as expectativas de professores sobre o desempenho escolar de seus alunos. Constataram que as atribuições para o fracasso escolar concentraram-se no campo de responsabilidade individual do aluno e de sua família, com destaque para o interesse, o esforço e as condições econômicas de seus integrantes.

Martini e Del Prette (2002) também investigaram as atribuições de causalidade para o sucesso e o fracasso escolar dos alunos por professoras do ensino fundamental. Evidenciaram a existência de uma tendência das docentes atribuírem o sucesso e o fracasso escolar aos alunos, embora reconhecessem a ação docente como fator importante de desenvolvimento e aprendizagem dos estudantes.

Em 2002 também foi realizada uma pesquisa (FERREIRA et al., 2002) com alunos brasileiros, argentinos e mexicanos. Essa pesquisa perguntava para os alunos a que eles atribuíam o fracasso e o sucesso escolar em relação ao seu próprio desempenho, ao dos colegas e de alunos de outras escolas e de outras nacionalidades. A amostra foi composta por 1594 estudantes, com bom ou mau rendimento escolar, de ambos os sexos, com idade entre $14 \mathrm{e}$ 20 anos, estudantes de escolas públicas e particulares. Os três grupos de alunos apontaram prioritariamente $\mathrm{o}$ esforço como causa explicativa do fracasso e do sucesso escolar próprio e também dos demais alunos.

Kaulfuss e Boruchovitch (2016) também realizaram pesquisa semelhante às anteriores, ou seja, com foco nas atribuições causais, mas com professores como público-alvo. Mais uma vez, as 
causas para o fracasso e o sucesso escolar giraram em torno do aluno e de suas respectivas famílias. Além disso, o sucesso em ensinar foi atribuído, mais frequentemente, a causas externas, estáveis e controláveis. Já o fracasso escolar a causas internas, instáveis e incontroláveis.

Assim, percebe-se que ao longo dos anos tem sido comum concepções advindas do senso comum de que se o aluno não vai bem na escola, isso se deve às suas limitações pessoais e ele é visto como alguém que não gosta de estudar, não consegue aprender ou não se esforça. Mas será que podemos centralizar as causas do fracasso escolar somente no aluno e/ou na sua família? Será que essa não seria uma explicação demasiada simplista e determinista? Advinda do senso comum? Afirmar que o aluno fracassa porque não se esforça não seria fruto de uma análise superficial e aparente da realidade que não leva em conta a totalidade do ser social? Esses são os questionamentos que instigaram esta pesquisa. Assim, objetivamos problematizar a concepção de que o fracasso escolar é de responsabilidade única e exclusivamente do aluno e as visões naturalizantes e positivistas acerca do ser humano, na tentativa de sua superação.

Nesse sentido, o referencial teórico e metodológico no qual essa análise se embasa é a teoria histórico-cultural (THC) e, por conseguinte, o materialismo histórico dialético (MHD). O ser humano deve ser reconhecido como síntese de muitas determinações (biológicas, históricas, culturais e sociais). Somente é possível uma compreensão mais ampla do ser humano se chegarmos à sua essência. A visão empírica, imediata e observável é apenas uma pequena parte do ser humano. Há que se chegar à sua essência e, para isso, torna-se necessário um processo de análise baseado no MHD. Duarte (2000) defende que a análise dialética é um processo fundamental para se compreender o ser humano. Há que se diferenciar a análise descritiva, superficial e imediata, daquela que avança para além da aparência e busca as determinações concretas do ser humano, considerando as esferas que compõem sua existência.

Considerando os pressupostos apresentados, no âmbito deste artigo apresentamos as bases do MHD e da THC que se constituem no referencial à luz do qual o fenômeno do fracasso escolar é analisado. Em seguida, analisamos o processo de abertura da escola pública às camadas populares e a problemática da garantia de uma educação de qualidade para essa parcela da população que se constitui na maioria dos indivíduos que atualmente ocupam as cadeiras escolares. $\mathrm{Na}$ sequência, analisamos o fracasso escolar segundo as dimensões sociais e psicológicas do fenômeno na tentativa de problematizar e superar a visão naturalizante e positivista do ser humano, e a consequente culpabilização do aluno pelo seu baixo rendimento escolar.

\section{As contribuições do materialismo histórico dialético e da teoria histórico-cultural para se pensar o fracasso escolar}

Segundo as bases do materialismo histórico dialético, teoria desenvolvida por Karl Marx, é por meio do trabalho realizado social e historicamente que o homem transforma a natureza ao seu redor adaptando-a às suas necessidades. No bojo das transformações materiais produz-se outra categoria, identificada como "trabalho não-material", isto é, a transformação material possibilita a produção do saber sobre o conjunto da produção humana (SAVIANI, 2000).

As especificidades inerentes aos trabalhos material e não-material exigem que diferentes abordagens sejam empregadas para sua compreensão e análise. No resultado de um trabalho material, como, por exemplo, a construção de uma cadeira, as etapas do processo de elaboração podem ser analisadas separadamente, proporcionando a identificação, verificação e correção das imperfeições existentes no produto final. Neste caso, a fragmentação do processo permite que o problema, caso exista, seja identificado e a etapa corrigida para o aperfeiçoamento do produto material.

Quando nos referimos às atividades humanas localizadas no trabalho não-material, tendo como exemplo o processo educativo, sua análise demanda um tratamento com maior complexidade. Pressupõe considerar as diferentes e variadas esferas concernentes às relações sociais, e inter-relacionadas, estabelecidas em diferentes contextos da existência humana.

Abordar o fracasso escolar buscando superar e questionar as visões simplistas e deterministas sobre suas causas que, de acordo com as pesquisas citadas anteriormente, 
culpabilizam o aluno e/ou sua família implica em lançarmos um olhar às bases do MHD e da THC, a fim de considerarmos elementos que contribuam para o processo de compreensão e análise do fenômeno.

De acordo com Leontiev (1978), no percurso histórico das discussões científicas, as abordagens biológica e hereditária, tidas como inatas do homem, foram subsidiárias às teses pseudobiológicas, que se configuraram como sendo reacionárias e racistas. Pelo caminho inverso, a ciência progressista, parte da ideia contrária, considerando "que o homem é um ser de natureza social, que tudo o que tem de humano nele provém da sua vida em sociedade, no seio da cultura criada pela humanidade." (LEONTIEV, 1978, p. 261, grifo do autor). Enquanto a primeira abordagem erige-se sob uma origem biológica-naturalizante, a primazia da segunda assenta-se sobre as interações sociais.

A origem animal do homem, evidenciada pelas pesquisas científicas, principalmente por Darwin, em sua obra "A Origem das Espécies", apontam para um processo de desenvolvimento inicial pautado nas leis biológicas, ainda que haja uma profunda distinção entre homens e animais. No entanto, a partir do momento em que o homem passa por um processo de hominização, isto é, a partir do instante em que sua vida passa a se organizar em sociedade tendo o trabalho como natureza dessa organização, ele deixa de estar sujeito às leis biológicas, submetendo-se às leis sócio históricas.

O homem assim constituído, no atual estágio em que se encontra, é detentor de todas as características biológicas necessárias ao seu pleno desenvolvimento sócio histórico. Seu corpo físico alcançou os elementos necessários ao seu aprimoramento cultural, não se sujeitando às transformações biológicas hereditárias para sua evolução, mas ao trabalho, enquanto atividade humana fundamental, criadora e produtiva. Dito de outra forma, as modificações biológicas hereditárias não são elementos determinantes para o desenvolvimento sócio histórico do homem e da humanidade, este processo passa a ser movido por outras forças que não as leis da variação e da hereditariedade biológica (LEONTIEV, 1978).

Estando a evolução do gênero humano não sob a égide da herança biológica, mas às leis sócio históricas, cada geração inicia sua vida em um mundo "pronto", em que a cultura (material e intelectual) foi criada e desenvolvida pelas gerações que a antecederam. Ao se apropriar dessas objetivações ela tem a possibilidade de transformá-la, contribuindo, assim, para o seu progresso. "Podemos dizer que cada indivíduo aprende a ser um homem. $O$ que a natureza lhe dá quando nasce não the basta para viver em sociedade. É-lhe ainda preciso adquirir o que foi alcançado no decurso do desenvolvimento histórico da sociedade humana." (LEONTIEV, 1978, p. 267, grifo do autor).

Assim posto, considerando o trabalho (material e não-material) como atividade vital para o gênero humano, a característica fundamental que contribui para a distinção dos outros animais é que o trabalho se configura em uma atividade realizada para determinado fim. Trata-se de uma ação premeditada e consciente objetivando o desenvolvimento de produtos com funções específicas definidas pela prática social. Nas palavras de Saviani e Duarte (2010, p. 426):

Por meio do trabalho o ser
humano incorpora, de
forma historicamente
universalizadora, a
natureza ao campo dos
fenômenos sociais. Nesse
processo, as necessidades
humanas ampliam-se,
ultrapassando o nível das
necessidades de
sobrevivência e surgindo
necessidades
propriamente sociais.

É por intermédio do contato com os outros indivíduos que ocorre a formação das faculdades humanas, efetivando-se a apropriação da experiência sócio histórica da humanidade. A criança em contato com os homens e com os fenômenos do mundo ao seu redor, através da comunicação, apropria-se das aquisições e objetivações daquilo que foi desenvolvido pelo gênero humano através do histórico da sociedade. "A apropriação dos instrumentos implica, portanto, uma reorganização dos movimentos naturais instintivos do homem e a formação de faculdades superiores." (LEONTIEV, 1978, p. 269).

As reflexões realizadas até o momento tiveram o intuito de apresentar as bases do MHD, enquanto concepção filosófica que considera a relação dinâmica e dialética existente entre as condições materiais da existência física e as dimensões sociais constituídas ao longo da 
história da humanidade. Foi com bases nessas premissas, desenvolvidas por Marx, que Vigotski desenvolveu a THC, considerando a natureza social da aprendizagem, na medida em que o aspecto social se sobrepuja ao biológico.

Questionando as teorias de sua época e procurando um novo caminho para tratar a relação entre aprendizagem e desenvolvimento da criança, Vigotski (1989) elabora uma nova solução para o problema. Estabelece como ponto de partida para sua teoria que a aprendizagem da criança começa antes de seu ingresso na escola, ou seja, as relações sociais experienciadas por ela, em contato com os adultos, oportunizam a aprendizagem. Por exemplo, ao adentrar a sala de aula a criança já domina aspectos da língua, que foram adquiridos pelas experiências vivenciadas por ela nas interações sociais das quais fez parte.

Diferentemente das demais teorias de sua época, para ele não há uma separação entre a aprendizagem e o desenvolvimento da criança, trata-se de processos inter-relacionados. Para Vigotski (1989), a orientação do ensino deve ser baseada em pelo menos dois níveis de desenvolvimento: o efetivo - aquele em que a criança pode realizar uma atividade sozinha - e o potencial - aquele em que ela precisa do auxílio de um adulto para realizá-la. Dessa forma, a identificação desses níveis corrobora o desempenho do trabalho docente.

As premissas do MHD sobre o desenvolvimento sócio histórico da humanidade e o processo de apropriação das construções materiais e não-materiais de uma geração pela outra considera que aquilo que provém do homem relaciona-se à sua vida em sociedade, estando submetido às leis sócio históricas. Da mesma forma que o trabalho se configura como uma ação premeditada e consciente que tem como objetivo o desenvolvimento de produtos, o trabalho educativo - a educação escolar - é também compreendido como uma ação realizada de forma organizada e premeditada cuja finalidade precípua é a apropriação da produção humana construída pelos homens.

Considerando que a proposição da THC evidencia o papel das interações sociais no processo de desenvolvimento e aprendizagem, e que cabe à educação, mais especificamente à escola, possibilitar meios para que as apropriações das construções materiais e nãomateriais se efetivem, considerando ainda que o indivíduo está inserido em um determinado tempo histórico, material e social, o fracasso escolar emerge como um revés na atualidade que precisa ser analisado vislumbrando a totalidade do ser social e as condições da realidade objetiva. Faz-se necessário a utilização de uma abordagem que se distancie da forma naturalizante simplista e determinista - de compreender o fenômeno e permita uma maior criticidade.

Em nossa perspectiva, por ser o fracasso escolar um fenômeno complexo e multifacetado, que engloba muito mais que a responsabilização do aluno e de sua família, uma abordagem dialética pautada nas premissas do MHD e da THC nos permite lançar um olhar mais crítico. É preciso considerar os demais atores envolvidos, o papel que cada um deles desempenha e as relações sociais que são estabelecidas, tanto interna, quanto externamente, à educação escolar. Assim, emerge a seguinte indagação: quais fatores, para além da (auto)culpabilização dos alunos e suas famílias, podem estar associados ao fracasso escolar? Com bases nessas questões passamos a abordar o fenômeno voltando nosso olhar para a totalidade do ser social e suas dimensões sociais e psicológicas.

\section{A abertura da escola pública às camadas populares}

Antes de adentrarmos nas questões mais específicas sobre o fracasso e/ou sucesso escolar, faz-se necessário refletirmos sobre questões anteriores, relacionadas à finalidade da educação. Diferentemente dos animais que se adaptam à natureza tendo sua subsistência garantida de forma natural, o ser humano, no caminho inverso, transforma a natureza adaptando-a as suas necessidades - ao transformar a natureza o homem transforma o mundo natural em mundo humano. Essa adaptação ocorre pelo trabalho, processo pelo qual o homem antecipa pelas ideias os objetivos de sua ação. Nessa representação estão incluídos aspectos como as propriedades da ciência, da ética e da arte, ou seja, propriedades do mundo real, valorização e simbolização, respectivamente (SAVIANI, 2000).

$\mathrm{Na}$ condição de trabalho não-material Saviani (2000) identifica duas categorias. Na primeira o produto se separa de seu produtor, como por exemplo, no caso de um livro, existindo um espaço entre a produção e o consumo. Já na segunda, estão localizadas as atividades em que o produto não se separa de seu ato de produção, como é o caso de uma aula - ao mesmo tempo 
em que o professor produz seu trabalho ele é consumido pelos alunos - e é neste local em que se encontra a educação. Então, o trabalho educativo é compreendido como o ato de produzir a humanidade construída histórica e coletivamente pelos homens. Nas palavras do autor:

Portanto, o que não é
garantido pela natureza
tem que ser produzido
historicamenter pelos
homens; e aí se incluem os
próprios homens.
Podemos, pois, dizer que a
natureza humana não é
dada ao homem, mas é
por ele produzida sobre a
base da natureza biofísica.
Consequentemente, o
trabalho educativo é o ato
de produzir, direta e
intencionalmente, em
cada indivíduo singular, a
humanidade que é
produzida histórica e
coletivamente pelo
conjunto dos homens.
(SAVIANI, 2000, p. 17).

Assim, tratar da temática do fracasso escolar implica, entre outros elementos, abordar o espaço em que se efetiva o ato de produção da humanidade no coletivo dos homens, ou seja, requer lançar um olhar sobre a escola. Em relação à questão de sua existência, Saviani (2000, p. 19-20) assevera que ela "existe, pois, para propiciar a aquisição dos instrumentos que possibilitam o acesso ao saber elaborado (ciência), bem como o próprio acesso aos rudimentos desse saber. As atividades da escola básica devem se organizar a partir dessa questão".

Ao realizar uma contextualização e análise da história da escola pública brasileira no século $X X$ o autor assevera que a mudança ocorrida no modelo educacional adotado pelo Estado sofreu alteração em virtude do desenvolvimento tanto da economia, quanto das cidades. O consequente aumento da demanda por educação substituiu o modelo rural e provinciano de atendimento escolar abrindo espaço para a oferta educacional em larga escala (SAVIANI et al., 2004).

A crescente democratização do ensino foi a responsável por mudanças significativas, exigindo que as reflexões realizadas em torno dessa temática considerem as características e especificidade de seu público vigente. Partindo, então, dessas premissas, pensar nas problemáticas atuais da educação, tais como o fracasso e/ou sucesso escolar, exige que observemos estas questões históricas e conjunturais, conforme faremos a seguir.

O histórico de existência da escola evidencia que se atualmente ela está acessível (ou ao menos deveria estar) à toda população, nem sempre foi assim. Como nos elucida Beisiegel (2005), que ao tratar da relação entre quantidade e qualidade da educação aborda a questão de transformação no caráter da escola de seletivo, para democrático. Esta transformação está relacionada à sua abertura para o atendimento às camadas mais pobres da população e ao aumento progressivo de sua escolaridade. Sobre as críticas existentes para esta transformação dos espaços escolares, o autor identifica dois padrões: as conservadoras e as radicais. Enquanto as primeiras olham para o passado afirmando que a escola atual perdeu sua qualidade, elas também utilizam os parâmetros do passado, de um período em que o ensino e os conteúdos eram voltados à formação dos filhos das elites. Já as segundas asseveram que a expansão da escola à população somente teria modificado o parâmetro de desigualdade, tanto no sistema de ensino, quanto na sociedade.

A evolução da escola, ou melhor dizendo, sua expansão quantitativa às camadas menos favorecidas da sociedade, resultou em novas relações internas, pois elas começaram a lidar com uma diversidade de frequentadores muito maior do que estavam acostumadas e, até mesmo, preparadas. Por conseguinte,

É preciso aceitar a escola como ela existe. Isso não significa aceitá-la integralmente, com suas distorções, burocratizada, ritualizada etc. Mas, aceitar, sobretudo, a qualidade da população que entrou na escola, que conquistou a escola. A escola do Brasil absorveu segmentos da população que não tiveram historicamente possibilidade de dominar a cultura dominante, que dá conteúdo à escola. (BEISIEGEL, 2005, p. 120). 
Se por um lado a ampliação das vagas à quase totalidade das crianças em idade escolar aumentou significativamente o número de matrículas, permitindo que as classes mais populares tivessem acesso à educação, por outro, as instituições tiveram que passar a lidar com problemáticas do cotidiano dessa população, mas que não estavam (talvez continuam não estando) preparadas. Assim, na atualidade, o desafio é "levar os jovens brasileiros não apenas à escola, mas também ao saber, às referências humanas fundamentais, ao espírito crítico e, se é que se pode sonhar, ao prazer de aprender" (IRELAND, 2007, p. 35).

Considerando as elucidações ora apresentadas faz-se necessário, como ponto de partida para os questionamentos sobre o fracasso escolar, com o objetivo de abordá-lo pelo âmbito da não-aprendizagem, lançar um olhar sobre a realidade do estudante que faz parte desta escola - Quais as condições materiais e não-materiais em que esses alunos estão inseridos? - Assim, no intuito de superar a visão do aluno como único ou grande responsável pelo fracasso escolar, em direção a um viés mais totalizador para o fenômeno, passamos a problematizar a questão considerando suas dimensões sociais e psicológicas.

\section{Considerações sobre a dimensão social do fracasso escolar}

Nessa dimensão trataremos mais especificamente sobre as implicações da desigualdade social e da família no fenômeno do fracasso escolar. É comum que se associe a pobreza, a desigualdade social ao fracasso escolar. Isso porque os índices de evasão e retenção apresentam-se mais elevados entre alunos das classes baixas (PATTO, 1990).

$A$ visão de que a criança pobre tem mais dificuldades no aprendizado dos conteúdos escolares foi corroborada pela chamada "Teoria da carência cultural", que se estabelece no pensamento educacional brasileiro a partir dos anos 70 do século XX. Na década de 80 , durante a realização de sua tese de doutorado, a pesquisadora Maria Helena de Souza Patto esteve durante um longo período em uma escola pública investigando o fenômeno do fracasso escolar. Teve como ponto de partida o fato de que as dificuldades de aprendizagem e, consequentemente, o fracasso escolar, incidiam sobre as crianças pobres com o argumento de que elas apresentavam problemas psicológicos, biológicos ou culturais. Sendo assim, a autora destaca o caráter ideológico e equivocado presente nessas explicações como resultado de concepções preconceituosas a respeito do pobre e da pobreza no Brasil. Pôde constatar também que existe uma série de questões institucionais, políticas, estruturais e de funcionamento da escola que conduzem as crianças e os adolescentes pobres ao fracasso escolar (PATTO, 1990).

Mais recentemente, a pesquisadora Nadir Zago (2011), também acompanhou a situação escolar de estudantes oriundos de famílias de baixa renda e pôde constatar que a interrupção dos estudos no ensino fundamental pode ocorrer ainda que esses estudantes tenham desempenhos positivos nas avaliações. "Em alguns casos, mas não sempre, a razão dessa interrupção está relacionada à necessidade de trabalho para auxiliar na sobrevivência familiar ou outra também não relacionada com o desempenho escolar." (ZAGO, 2011, p. 60).

O Brasil tem um problema sério de desigualdade social que precisa ser resolvido, mas não é porque o aluno é pobre que ele não aprende e sai da escola. A questão econômica acaba levando a outros fatores: o aluno sai da escola porque tem que trabalhar para ajudar a família ou ele é um estudante que trabalha o dia todo e vai para a escola no período noturno, estuda com muita dificuldade e nem sempre alcança êxito. Às vezes ele estuda em uma escola que falta infraestrutura básica para as aulas, falta professor, falta material didático. Em outras palavras, não é somente o fato de o aluno ser pobre, mas as condições sociais que o cerca em decorrência da pobreza.

Para que possa se desenvolver plenamente, o indivíduo precisa se apropriar e dominar o sistema de referências que faz parte do contexto em que vive. Dessa forma, poderá "objetivar-se como sujeito ativo e participante das transformações desse contexto" (OLIVEIRA, 2005 , p. 29). No entanto, as possibilidades de apropriação dos conhecimentos da produção humana não são dadas a todos os indivíduos. Nesse sentido, nos diz Betty Oliveira $(2005$, p. 29) que:

Tal produção, em
princípio, estaria à
disposição de todos os
indivíduos para que eles,
com base em uma escolha


feita livremente, pudessem apropriar-se delas e, assim, dominá-las para poder utilizá-las como instrumental de sua atuação ativa e efetiva no contexto onde vivem. Está implícito aí que o impedimento dessa apropriação por cada indivíduo o torna "marginalizado" ou, como vem sendo denominado ultimamente, "excluído".

O aluno oriundo de uma classe econômica menos favorecida, muitas vezes, é excluído da possibilidade de se apropriar e dominar o sistema de referências que o cerca, bem como de ter acesso aos conhecimentos sistematizados pela humanidade. $\mathrm{E}$ isso por vários fatores. Pela própria condição econômica e também pela situação precária em que se encontra a formação, o trabalho dos professores e as escolas de modo geral. Se a escola não favorece a apropriação dos conhecimentos científicos pelas classes populares, acaba por colaborar com a manutenção da ordem vigente e a elitização do saber (DUARTE, 2000). Além disso, a escola deixa de cumprir a sua função de transmissão-assimilação do conhecimento clássico acumulado pela humanidade através dos tempos (SAVIANI, 2000).

A desigualdade social reflete na sala de aula e se conseguíssemos diminuí-la talvez melhoraríamos nossos índices de evasão e retenção. $O$ combate ao fracasso escolar requer uma atuação contra a desigualdade social, a miséria, a favor de condições dignas de trabalho e formação para professores, e de condições de estudo para os alunos.

É preciso atenção e cautela para não cair no equívoco de concluir que "o problema do fracasso escolar seria resolvido se os alunos pobres e suas famílias se esforçassem" (IRELAND, 2007 , p. 36). Isso implica em desconsiderar que o sujeito faz parte de um contexto mais amplo, como se indivíduo e sociedade fossem polos opostos, descolados um do outro. "Do ponto de vista ontológico, não há antagonismo entre homem e sociedade, pois na realidade são polos complementares de um mesmo processo." (OLIVEIRA, 2005, p. 33). Segundo a abordagem ontológica, a qual defendemos que deve embasar os estudos sobre o fenômeno do fracasso escolar, o foco de análise deve voltar-se para a realidade objetiva concreta, histórica e social da espécie humana.

Acerca da família, afirmar, por exemplo, que o aluno fracassa na escola porque provém de uma família "desestruturada", cujos pais são violentos, não valorizam a escola, não dão atenção, ficam muito tempo fora de casa, são separados, alcoólatras etc., implica na necessidade de algumas ponderações. Não podemos desconsiderar que este aluno faz parte de um sistema e de uma organização social que transcende, que é muito maior do que sua família nuclear. Isso não quer dizer que a família não tenha influência sobre a educação dos filhos, mas não pode ser considerada como fator único e determinante para o fracasso escolar.

A impossibilidade de os pais acompanharem seus filhos para que estes tenham bom êxito na escola, ou de lhes fornecer condições econômicas e culturais mínimas, pode influenciar, assim como outros aspectos, mas não pode ser entendida como fator determinante e exclusivo (SILVA, 2003). Caso contrário, corremos o risco de estigmatizar e rotular esse aluno, o que gera um comodismo para as escolas e para os professores, que não precisam rever suas aulas, suas metodologias de ensino, já que o problema é do aluno e de sua família.

Além disso, existe no imaginário social dos profissionais da educação uma "família idealizada" que muitas vezes não corresponde à família real, constituída por pais que "sofrem com trabalhos (ou a falta deles) desgastantes, esforçam-se para que o salário dure até o fim do mês e preocupam-se com o bem-estar dos seus filhos, embora nem sempre saibam como garantiIo" (ASBAHR; LOPES, 2006, p. 65). Ao vislumbrar um ideal de família, a escola distancia-se cada vez mais dos pais de seus alunos. "A relação famíliaescola torna-se tensa e sofrida: os pais sentem-se humilhados por cobranças agressivas; os professores sentem-se desvalorizados e solitários com o afastamento dos pais." (ASBAHR; LOPES, 2006, p. 65).

\section{Considerações sobre a dimensão psicológica do fracasso escolar}

Ainda que a THC forneça subsídios importantes para se pensar as dimensões psicológicas do fracasso escolar, tendo em vista outros conceitos como, por exemplo, as funções psíquicas superiores e as atividades de estudos, optamos, no espaço deste artigo, por abordar as 
questões relacionadas à medicalização e patologização da educação. Essa escolha se justifica por entendermos que tal fenômeno é complexo e multifacetado, o que nos incitou a tratar de elementos que estão relacionados diretamente à culpabilização do aluno.

O termo medicalização da educação é utilizado para nomear uma prática de "biologização da educação" realizada pela ciência médica e concretizada na ação dos profissionais médicos. Recentemente, com a ampliação dos campos dos conhecimentos, outros profissionais estão envolvidos nesse processo: psicólogos, fonoaudiólogos, psicopedagogos etc., que vêm se juntar aos médicos em sua prática biologizante. "Daí a substituição do termo medicalização por um outro mais abrangente - patologização -, uma vez que o fenômeno tem-se ampliado, fugindo dos limites da prática médica" (COLLARES; MOYSÉS, 1994, p. 26).

Ocorre que, como as explicações sobre o fracasso escolar são centralizadas no aluno, se ele não se adapta à escola, se não obtêm êxito, já se pensa logo que ele deva ter algum problema de cunho intelectual, emocional, físico, e esse aluno é encaminhado para o psicólogo, fonoaudiólogo, psicopedagogo e muitas vezes medicalizado por supostamente apresentar algum "distúrbio", algum "problema".

O estudo de Silva (2003) revelou que a faixa etária predominante de crianças que são encaminhadas ao psicólogo é de 7 a 10 anos, período em que é comum apresentarem dificuldades no que tange ao processo de alfabetização e à adequação às rotinas escolares, sendo que a maioria dos encaminhamentos $(63,0 \%)$ analisados pela pesquisadora corresponde a alunos que estão cursando o 1 응 ano do ensino fundamental. Claro que tais dificuldades, muitas vezes, não estão relacionadas, necessariamente, a alguma patologia:

As dificuldades de aprendizagem se referem à não alfabetização plena, - que ainda pode ser esperado por uma criança que cursa a 1 a série e que não se alfabetizou na préescola. As dificuldades de comportamento se referem, na maioria das vezes, à dificuldade em responder às rotinas escolares, como permanecer sentado na carteira, não conversar, o que também pode ser esperado em crianças com essa idade. (SILVA, 2003, p. 51).

Muitas dessas crianças saem dos consultórios com algum diagnóstico de patologia e/ou ainda portando um receituário médico. Assim, medicalização e patologização são processos em que questões que são do âmbito das políticas sociais, da cultura, da nossa forma de viver, acabam sendo transformadas em problemas médicos, em doenças, em transtornos, em distúrbios, ou seja, questões que são do âmbito social acabam sendo assumidas como problemas dos indivíduos, das pessoas, privilegiando a abordagem biológica, organicista (COLLARES; MOYSÉS, 1994) que permeou os primeiros estudos sobre as dificuldades de aprendizagem no século XIX.

Esses estudos centralizavam as explicações sobre as dificuldades de aprendizagem "nas noções de congenitabilidade e hereditariedade, atribuindo todas as perturbações que não fossem causadas por lesão cerebral a disfunções neurológicas ou a retardos de maturação imputados a um equipamento genético defeituoso" (BOSSA, 2002, p. 23). Acreditava-se, portanto, que as dificuldades de aprendizagem provinham das diferenças biológicas naturais dos indivíduos, desconsiderando a natureza social humana e a diversidade das relações estabelecidas com os objetos culturais (LEONTIEV, 1978).

Depois disso, passamos pela "era da psicometria" com a criação dos chamados testes de inteligência. "A partir daí o fracasso escolar foi associado ao déficit intelectual, ou seja, um baixo QI (Quociente de Inteligência), de forma que boa aprendizagem e inteligência formavam, portanto, um binômio muito firme, e qualquer fracasso se relacionava, automaticamente, com debilidade mental." (BOSSA, 2003, p. 23). Parece que desse período até os dias atuais, apesar dos avanços, muitas vezes, continuamos a imputar o problema do fracasso escolar a causas biológicas, patológicas, que adquire um viés de culpabilização do indivíduo:

[...] recorre-se ao reducionismo biológico, segundo o qual a situação de vida e o destino de indivíduos e grupos 
poderiam ser explicados por - e reduzidos - a características individuais. Por essa visão de mundo, as circunstâncias sociais, políticas, econômicas e históricas teriam mínima influência sobre a vida das pessoas; daí decorre que o indivíduo seria o maior responsável por seu destino, por sua condição de vida, por sua inserção na sociedade. (COLLARES; MOYSÉS, 1994, p. 26).

A sociedade brasileira tem demonstrado muita dificuldade em relação ao acesso, à permanência, à qualidade da educação e não tem conseguido superar essas dificuldades no campo educacional. Ao invés de problematizarmos e refletirmos sobre que tipo de escola/educação estamos ofertando, procuramos encontrar nos alunos, dificuldades de aprendizagem, como se fosse uma coisa dele, individual, fora de um contexto de escolarização, mais amplo e complexo. Logo, esse aluno é encaminhado para o psicólogo, para o fonoaudiólogo, para o psicopedagogo e muitas vezes diagnosticado como tendo algum problema, como por exemplo, Transtorno de Déficit de Atenção e Hiperatividade (TDAH), dislexia, distúrbios emocionais ou neurológicos, disfunção cerebral mínima etc. E, então, é medicado.

O cenário que temos hoje é de um grande número de alunos sendo encaminhado para esses profissionais da área de saúde, bem como fazendo uso de medicamentos. O mais comum deles é o metilfenidato, mais conhecido como Ritalina. O Instituto Brasileiro de Defesa do Usuário de Medicamentos (IDUM) divulgou que entre 2000 e 2008 a venda desse remédio saltou de 71.000 caixas para mais de 1 milhão. Em 2010 esse número dobrou para 2.1 milhões $\mathrm{e}$ continuou apresentando crescimento ano a ano. Segundo dados da Agência Nacional de Vigilância Sanitária (Anvisa), o número de caixas de metilfenidato vendidas no Brasil aumentou para 2.6 milhões em 2013. O Brasil é o 2o país do mundo que mais consome Ritalina, perdendo apenas para os EUA.

E aí se tornam inevitáveis os seguintes questionamentos: será que todos esses alunos deveriam ser encaminhados a esses profissionais? Será que todos realmente possuem algum distúrbio, algum transtorno de aprendizagem? Será que isso não revela a dificuldade que as escolas vêm enfrentando no processo de escolarização dos alunos? Ou a dificuldade das famílias em lidarem com os problemas educacionais de seus filhos? Centralizar as causas do fracasso escolar no aluno é uma situação mais cômoda, se ele não aprende é porque tem algum problema. A aprendizagem e a não-aprendizagem são consideradas como algo individual, inerente ao aluno, e o diagnóstico é centrado nele, chegando, ao máximo, até sua família. Quer dizer, a sociedade, a escola e os professores não têm responsabilidade nenhuma, pois o problema está no aluno: "Tudo está indo muito bem, pena que $50,0 \%$ a $70,0 \%$ de Joãozinhos e Mariazinhas, individualmente, tenham problemas de saúde, sejam imaturos, desajustados, carentes [...]" (COLLARES, 1992, p. 27).

É claro que existem casos que necessitam de intervenção clínica, mas o que hoje se apresenta como um quadro preocupante é a crescente medicalização dos alunos diante do fracasso escolar, como se outros fatores não estivessem relacionados a ele. A situação é tão preocupante que a cidade de São Paulo aprovou uma Lei (no 15.554/12) que implantou o dia municipal e estadual de luta contra a medicalização da educação, que é o dia 11 de novembro. Assim como Machado (2000, p. 146) entendemos que:

[...] existem pessoas com distúrbios, existem lesões que prejudicam $\mathrm{o}$ processo ensinoaprendizagem, existe pobreza, existem problemas emocionais, familiares, pais alcóolatras, professores percebendo problemas individuais na criança. Existem crianças que merecem atendimento psicoterápico, pois estão sofrendo e paralisadas. Mas não é possível estabelecermos uma relação direta de causa e efeito entre essas questões e a capacidade de aprender [...].

Percebe-se que existe uma demasiada preocupação por diagnósticos e laudos que 
expliquem e justifiquem a dificuldade de aprendizagem, mas o mais preocupante é que realizado o diagnóstico cessam as preocupações com o aprendizado do estudante, uma vez que a explicação para a não aprendizagem já está dada e não há o que fazer (COLLARES; MOYSÉS, 1994). Dessa forma, "são os alunos individualmente que não têm capacidade de aprender, são eles os grandes problemas da escola, reduzidos a meros objetos, independentes das dimensões sociais e políticas das instituições escolares, nas sociedades divididas em classes" (ASBAHR; LOPES, 2006, p. 60).

Asbahr e Lopes (2006) destacam que os laudos, muitas vezes, se referem a crianças abstratas, por meio de estereótipos. Limitam-se "ao uso de procedimentos técnicos de avaliação e de jargões recheados de preconceito" (ASBAHR; LOPES, 2006, p. 60) desconsiderando as condições reais em que as dificuldades de aprendizagem são produzidas. Com o laudo em mãos, os professores continuam perdidos, sem saber o que fazer, ou seja, os diagnósticos acabam por não auxiliar em nada a prática pedagógica e podem levar o professor a desistir de ensinar (ASBAHR; LOPES, 2006).

$O$ estudante ganha um rótulo e acaba por introjetar a "doença". "Passa a ser psicologicamente uma criança doente, com consequências previsíveis sobre sua autoestima, sobre seu autoconceito e, aí sim, sobre sua aprendizagem. $\mathrm{Na}$ prática, ela confirma o diagnóstico/rótulo estabelecidos." (COLLARES; MOYSÉS, 1994, p. 29). Como postula Vigotski $(1989$, p. 114) a linguagem "transforma-se em função mental interna que fornece os meios fundamentais do pensamento da criança". Dessa forma, a criança aprende a controlar seu comportamento através das palavras. Palavras ditas repetidas vezes, são internalizadas pelos estudantes - doença dita, doença aceita e introjetada.

\section{CONSIDERAÇÕES FINAIS}

Diante do explicitado no âmbito deste artigo, podemos concluir que o fracasso escolar pode ser compreendido como um fenômeno complexo. Para além da responsabilização do aluno e de sua família, há que se considerar a totalidade do ser social e as condições objetivas da realidade concreta. Considerando o processo das gerações se apropriarem das construções materiais e intelectuais das gerações precedentes, considerando ainda que cabe à educação, mais especificamente à escola, possibilitar meios para que essas aquisição/apropriação se concretize, considerando ainda que o indivíduo está inserido em uma sociedade e que nela ele se relaciona com outros indivíduos, que desempenham diferentes papéis, como compreender/analisar/questionar o fracasso escolar senão por uma vertente mais totalizadora do processo educativo?

Assim, objetivamos refletir acerca das dimensões sociais e psicológicas do fracasso escolar à luz da THC, na tentativa de que pudéssemos compreendê-lo em sua essência, em sua totalidade, para além da aparência, do senso comum e, portanto, da culpabilização do aluno. Por isso é importante assinalar que é necessário levar em consideração também as dimensões cultural, pedagógica e política do fenômeno. Isso implica em problematizar as questões concernentes aos conteúdos e às metodologias de ensino, à valorização do saber, da escola e dos professores - para citar alguns exemplos -, o que não nos foi possível no espaço deste artigo.

Além disso, também é importante salientar que é notório e crescente a culpabilização do professor pelo fracasso escolar dos estudantes. Optamos por analisar a problemática da responsabilização do aluno pelos resultados alcançados no processo de ensino e aprendizagem. Mas defendemos que seria importante refletir sobre o tema em conjunto com a problemática de responsabilização do outro polo, o professor, ampliando-se o leque de análise, uma vez que ele é o sujeito cujo papel é preponderante no processo educativo do aluno.

Lançar um olhar crítico sobre o fenômeno do fracasso escolar implica em revelar nossa dificuldade enquanto sociedade, corporificada em nossos sistemas de ensino, instituições escolares e profissionais da educação em lidar com os desafios advindos da democratização do ensino, ou seja, com o acesso das camadas populares à escola pública. Dessa forma, o fracasso escolar acaba sendo tratado como um problema de cunho individual. Em consonância com os pressupostos da THC, acreditamos que os estudantes, se submetidos a uma educação de qualidade, poderão desenvolver inúmeras potencialidades e avançar no seu processo de desenvolvimento e humanização.

\section{REFERÊNCIAS}


ASBAHR, F. S. F.; LOPES, J. S. A culpa é sua. Psicologia USP, v. 17, n. 1, p. 53-73, 2006. Disponível em: https://www.scielo.br/scielo.php?script=sci artte xt\&pid=S010365642006000100005\&lng=pt\&tlng=pt. Acesso $\begin{array}{llll}\text { em: } & 15 & \text { out. } & \end{array}$

https://doi.org/10.1590/S0103$\underline{65642006000100005}$

BEISIEGEL, C. R. A qualidade do ensino na escola pública. Brasília: Líber Livro Editora, 2005.

BRASIL. Agência Nacional de Vigilância Sanitária (Anvisa). 2019. Disponível em: http://portal.anvisa.gov.br/. Acesso em: 19 out. 2019.

BRASIL. Instituto Brasileiro de Defesa dos Usuários de Medicamentos (IDUM). 2019. Disponível em: http://idum.org.br/. Acesso em: 19 out. 2019.

BRASIL. Ministério da Educação. Instituto Nacional de Estudos e Pesquisas Educacionais Anísio Teixeira - Inep. Indicadores Educacionais. Brasília, 2019. Disponível em: http://inep.gov.br/web/guest/indicadoreseducacionais. Acesso em: 15 set. 2019.

BOSSA, N. A. Fracasso escolar: um olhar psicopedagógico. São Paulo: Artmed, 2002.

COLLARES, C. A. L. Ajudando a desmistificar o fracasso escolar, Série Ideias, São Paulo, n. 6, p. 24-28, 1992.

COLLARES, C. A. L.; MOYSÉS, M. A. A. A transformação do espaço pedagógico em espaço clínico (A patologização da educação), Série Ideias, São Paulo, n. 23, p. 25-31, 1994.

DUARTE, N. Vigotski e o "aprender a aprender": crítica às apropriações neoliberais e pósmodernas da teoria vigotskiana. Campinas: Autores Associados, 2000.

FERREIRA, M. C. A.; ASSMAR, E. M. L.; OMAR, A. G.; DELGADO, H. U.; GONZÁLEZ, A. T.; SILVA, J. M. B.; SOUZA, M. A.; CISNE, M. C. F. Atribuição de causalidade ao sucesso e fracasso escolar: um estudo transcultural Brasil - Argentina - México. Psicologia: Reflexão e Crítica, v.15, n.3, p. 515527, 2002. Disponível em: https://www.scielo.br/scielo.php?script=sci artte xt\&pid=S0102-

79722002000300006\&lng=pt\&nrm=iso\&tlng=pt.

Acesso em: 16 out. 2019.

https://doi.org/10.1590/S0102-

$\underline{79722002000300006}$

GAMA, E. M. P.; JESUS, D. M. Atribuições e expectativas do professor: representações sociais na manutenção da seletividade social na escola. Psicologia: Teoria e Pesquisa, v. 10, n. 3, p. 393410, 1994.

IRELAND, V. E. (Org.) Repensando a escola: um estudo sobre o desafio de aprender, ler e escrever. Brasília: UNESCO, MEC/INEP, 2007.

KAULFUSS, M. A.; BORUCHOVITCH, E. Atribuições causais de professores para o sucesso e fracasso escolar. Psicologia Escolar e Educacional, São Paulo, v. 20, n. 2, p. 321-328, maio/ago, 2016. Disponível em: https://www.scielo.br/scielo.php?script=sci artte xt\&pid=S1413-

$85572016000200321 \& \operatorname{lng}=$ pt\&tlng=pt. Acesso em: 17 out. 2019. https://doi.org/10.1590/2175$\underline{353920150202974}$

LEONTIEV, Alexis. 0 desenvolvimento do psiquismo. Lisboa: Horizonte Universitário, 1978.

MACHADO, A. M. Avaliação psicológica na educação: mudanças necessárias. In: TANAMACHI, E. R.; PROENÇA, M.; ROCHA, M. L. (Org.). Psicologia e educação: desafios teóricopráticos. São Paulo: Casa do Psicólogo, 2000.

MARTINI, M. L.; DEL PRETTE, Z. A. P. Atribuições de causalidade para o sucesso e o fracasso escolar por professoras do ensino fundamental. Interação em Psicologia, v. 6, n. 2, p. 149-156, $2002 . \quad$ Disponível em: https://revistas.ufpr.br/psicologia/article/view $/ 3$ 302. Acesso em: 18 out. 2019. https://doi.org/10.5380/psi.v6i2.3302.

OLIVEIRA, B. Dialética do singular-particularuniversal. In: ABRANTES, A. A.; SILVA, N. R.; MARTINS, S. T. F. (Orgs.). Método histórico-social na psicologia social. Petrópolis: Vozes, 2005.

PATTO, M. H. S. A produção do fracasso escolar: histórias de submissão e rebeldia. São Paulo: T. A. Queiroz, 1990. 
PEZZI, F. A. S.; MARIN, A. H. Fracasso escolar na educação básica: revisão sistemática da literatura. Temas em Psicologia, v. 25, n. 1, 2017. Disponível em: http://pepsic.bvsalud.org/pdf/tp/v25n1/v25n1a0 1.pdf. Acesso em: 20 out. 2019. https://doi.org/10.9788/TP2017.1-01

SAVIANI, D. Pedagogia histórico-crítica: primeiras aproximações. Campinas: Autores Associados, 2000.

SAVIANI, D. et al. O legado educacional do século $\mathbf{X X}$ no Brasil. Campinas: Autores Associados, 2004.

SAVIANI, D.; DUARTE, N. A formação humana na perspectiva histórico-ontológica. Revista Brasileira de Educação, Rio de Janeiro, v. $15 \mathrm{n}$. 45, p.422-433, set./dez. 2010. Disponível em: https://www.scielo.br/scielo.php?script=sci artte xt\&pid=S1413-

24782010000300002\&lng=pt\&t|ng=pt. Acesso em: $\quad 15 \quad$ out. 2019.

https://doi.org/10.1590/S1413$\underline{24782010000300002}$

SILVA, A. C. A. Dimensões do sucesso e fracasso escolar: estudo dirigido à infância. 2003. $166 \mathrm{f}$. Dissertação (Mestrado em Educação) Universidade Estadual de Campinas, Campinas, 2003.

VIGOTSKI, L. S. Aprendizagem e desenvolvimento intelectual na idade escolar. In: VIGOTSKI, L. S. LURIA, A. R. LEONTIEV, A. N. Linguagem, desenvolvimento e aprendizagem. São Paulo: Ícone, 1989.

ZAGO, N. Fracasso e sucesso escolar no contexto das relações família e escola: questionamentos e tendências em sociologia da educação. Revista Luso-brasileira, v.2, n. 3, 2011. 